\title{
Consumo vegetariano na contemporaneidade: uma reflexão a partir do conceito de política-vida de Giddens
}

\author{
Virginia Therezinha Kestering ${ }^{1}$ \\ Recebido em março de 2020 \\ Aceito em junho de 2020
}

\begin{abstract}
RESUMO
O objetivo deste texto é abordar a atitude reflexiva em relação à alimentação a partir da esfera do consumo utilizando a adoção da dieta vegetariana como estudo de caso e tendo como abordagem a teoria da reflexividade, em especial a abordada por Giddens. $\mathrm{O}$ termo reflexividade tem sido abordado em diferentes escolas sociológicas. No que tange a sociologia da alimentação, muitas vezes ele é utilizado para referenciar os consumidores que assumem uma postura alternativa em relação ao consumo de alimentos como os vegetarianos, por exemplo. $\mathrm{O}$ ato de comer é central na nossa relação com as outras espécies animais. Nesse sentido, na primeira parte deste texto, proponho uma discussão a esse respeito, em especial no que tange a percepção e a relação entre humanos e animais em um sistema de produção de carne industrial. Na segunda parte me atenho a discussão específica a respeita da dieta vegetariana como uma identidade alimentar que procura contestar a cultura e as forma de produção vigente. Em função dessa característica questiono em que medida ela se enquadra a uma estratégia de estilo de vida que Giddens denominou de política-vida, uma forma de subjetivação baseados em um modo de fazer política distinta dos modos tradicionais de luta pela emancipação. A partir do diálogo com o trabalho de Micheletti e Stolle (2010), argumento que tanto os vegetarianos motivados por questões éticas quanto por questões pessoais podem ser compreendidos a partir dos conceitos da política-vida.
\end{abstract}

Palavras-chave: Vegetarianismo; Política-vida; Alimentação.

\section{Vegetable consumption in contemporary society: considerations based on the Life Politics concept by Giddens.}

\begin{abstract}
This text aims to address the reflexive attitude towards food from the sphere of consumption using the adoption of the vegetarian diet as a case study and taking the theory of reflexivity as an approach, especially that approached by Giddens. The term reflexivity has been approached in different sociological schools. Regarding the sociology of food, it is often used to refer to consumers who take an alternative stance about food consumption, such as vegetarians, for example. Eating is central to our relationship with other animal species. In this sense, in the first part of this text, I propose a discussion in this regard, especially regarding the perception and the relationship between humans and animals in an industrial meat production system. In the second part, I focus on the specific discussion regarding the vegetarian diet as a food identity that seeks to challenge the culture and forms of production in force. As a result of this characteristic, I question to what extent it fits into a lifestyle strategy that Giddens called life-politics, a form of subjectivation based on a way of doing politics distinct from the
\end{abstract}

\footnotetext{
1 Doutoranda em Sociologia da Universidade Federal do Paraná. Bolsista CAPES. E-mail: vikestering@gmail.com
} 
traditional ways of fighting for emancipation. From the dialogue with the work of Micheletti and Stolle (2010), I argue that both vegetarians motivated by ethical and personal issues can be understood from the concepts of life-politics.

Keywords: Vegetarianism; Life-politics; Food.

A seleção alimentar humana não é arbitrária ou irrefletida. Nosso status de onívoro nos permite que escolhamos e tais escolhas marcam não só os vegetais e animais que são rejeitados como comida, como também os hierarquizamos e os significamos (MONTANARI, 1988). Nossas escolhas alimentares são reflexo de uma complexa interação entre fatores culturais, sociológicos, biológicos, nutricionais e psicológicos (BLADES, 2001; POULAIN, 2003). Essas organizações alimentares, contudo, não são estruturas fixas. Embora a permanência de determinados hábitos por longos períodos de tempos possa reforçar uma ideia de que eles sempre estiveram ali - ou sempre foram assim -, eles são resultado de longos e emaranhados encontros e contaminações que se auto influenciam e não tem uma origem definida. No entanto, essa natureza móvel da alimentação é, por vezes, pouco percebida dentro das estruturas tradicionais. A vivência coletiva e a hereditariedade dos hábitos podem facilmente gerar uma sensação de perenidade.

A experiência da perenidade dos costumes alimentares, no entanto, tem diminuído com a emergência da globalização. Mesmo que por vários aspectos se mantenha uma relação estreita com a cultura local, a identidade, o gosto ou os sistemas simbólicos, a comida tem sido produzida como uma mercadoria em um sistema agroalimentar cada vez mais global. Como produto mercadológico, os alimentos muitas vezes são fetichizados e sujeitos ao calor da moda (JOHNSTON \& SZABO, 2010). Nesse sistema, os comensais, agora consumidores, passam a ter a chance de ter ao seu dispor um conjunto cada vez maior de alimentos distintos e, dependo das condições, em maior quantidade. Dessa forma, o consumo alimentar se torna um campo particularmente frutífero para as mudanças (BEARDSWORTH \& KEIL,1997, p. 68).

Assim como ocorre em várias outras instâncias das sociedades modernas, uma das consequências desse sistema é a crescente sensação de individualização em torno 
das escolhas alimentares (BEARDSWORTH \& KEIL, 1997; FISCHLER \& MASSON, 2010; JOHNSTON \& SZABO, 2010). A possibilidade de escolher comer um pão de fermentação natural no café da manhã, comida caseira no almoço e mexicana no jantar transmite ao consumidor uma experiência de poder e não sujeição aos costumes e tradições. Contudo, essa experiência é, com frequência, alienante, pois foca nos desejos individuais construídos pela indústria e esconde as consequências coletivas de sua produção, como desigualdade sociais, crises ambientais, desemprego, etc. (GUTHMAN, 2007). No entanto, é na esfera do consumo individual que muitas pessoas procuram combater as contradições da alimentação da modernidade. A tendência a reflexividade na modernidade tardia (GIDDENS, 2002) permite que os sujeitos exerçam a sua cidadania a partir da escolha do que adicionar a sua lista de supermercado conferindo aos consumidores o status de atores no sistema político, embora até mesmo essas práticas possam, com frequência, ser usada pelo neoliberalismo como estratégia de lucro e aumento de vendas (JOHNSTON \& SZABO, 2010).

É dentro desse conjunto de consumidores que buscam salvar o mundo através das compras no supermercado que situo os vegetarianos. O objetivo deste texto é abordar essa atitude reflexiva em relação à alimentação a partir da esfera do consumo utilizando a adoção da dieta vegetariana como estudo de caso e tendo como abordagem a teoria da reflexividade, em especial a abordada por Giddens (2002). Nos últimos anos, o número de pessoas que se consideram vegetarianas têm aumentado em várias partes do mundo. De acordo com a pesquisa IBOPE realizada em 2018, 14\% da população brasileira se considera vegetariana, um aumento de seis pontos percentuais em relação à última pesquisa feita em 2012. Nas regiões metropolitanas de São Paulo, Recife, Curitiba e Rio de Janeiro essa proporção é ainda maior, representando cerca 16\% dos habitantes dessas cidades (IBOPE, 2018).

A teoria da reflexividade apresenta uma grande oportunidade para compreender as motivações individuais que são perpassadas por consequência políticas e globais, como transformações sociais, econômicas e ambientais. O termo reflexividade tem sido abordado em diferentes escolas sociológicas. No que tange a sociologia da alimentação, muitas vezes ele é utilizado para referenciar os consumidores que assumem uma postura alternativa em relação ao consumo de 
alimentos (GUTHMAN, 2003; JOHNSTON \& SZABO, 2010), como os vegetarianos, por exemplo. No entanto, como condição específica da modernidade, a meu ver ela tangencia vários aspectos das escolhas e, consequente, construção da identidade alimentar.

O ato de comer é central na nossa relação com as outras espécies animais. Nesse sentido, na primeira parte deste texto, proponho uma discussão a esse respeito, em especial no que tange a percepção e a relação entre humanos e animais em um sistema de produção de carne industrial. Procuro demonstrar como os animais e a consequente produção e consumo de carne mudaram radicalmente na modernidade tardia em relação às sociedades tradicionais criando riscos que, em geral, se tornam responsabilidade dos indivíduos em gerenciar. É contra esse contexto que muitos vegetarianos se posicionam ao negar o consumo de proteína animal.

Na segunda parte me atenho a discussão específica a respeita da dieta vegetariana como uma subjetividade alimentar que procura contestar a cultura e as forma de produção vigente. Em função dessa característica questiono em que medida ela se enquadra a uma estratégia de estilo de vida que Giddens (2002) denominou de política-vida, uma forma de subjetivação baseados em um modo de fazer política distinta dos modos tradicionais de luta pela emancipação. A política-vida se configura como uma condição sui generis da modernidade atrelada às influências globalizantes que perpassam o local e o privado (GIDDENS, 2002). Embora eu reconheça a existência de atores que aderem à militância política coletiva do vegetarianismo e da defesa dos animais, o objetivo deste texto é abordar o vegetarianismo como uma expressão de um projeto reflexivo de pessoas que procuram dar sentido e controlar as ansiedades inerentes da modernidade tardia a partir de uma concepção moral a respeito dos animais e do meio-ambiente. Nesse sentido, me questiono em que medida a escolha alimentar baseada na rejeição da carne ou de outros produtos de origem animal se constitui como uma política de vida. Para Micheletti e Stolle (2010), somente quando essa decisão é motivada por razões não pessoais, como a melhora da saúde, ela poderia ser entendida como uma política-vida. No entanto, a partir do diálogo com esses autores, argumento que tanto os vegetarianos motivados por questões éticas quanto por questões pessoais podem ser compreendidos a partir desse conceito. 


\section{Os animais na modernidade tardia: a produção de riscos de um sistema industrial de carnes.}

Os animais sempre ocuparam um espaço privilegiado na dieta humana (FIDDES, 2004; FRANKLIN, 1999). Embora nossa relação com essas criaturas não se resuma a comida e comedor, sendo definida pelos mais diversos tipos de associações, essa é uma de grande importância. De acordo com o estudo de Fiddes (2004) realizado na Grã-Bretanha, o apreço dado ao consumo da carne se estende para além da sua importância nutricional. Ele se configura como uma escolha "natural" para muitas sociedades e representa uma forma de expressar seu controle sobre a natureza - um valor altamente importante da modernidade.

Essa predileção especial pela carne fez deste um alimento especial, em contraste com todos os demais (FRANKLIN, 1999). Como consequência desses fatores, a carne é amplamente associada à poder, status e, portanto, à construção social da masculinidade. (ADAMS, 2012;1991; BOURDIEU, 2007; FIDDES, 2004; FRANKLIN, 1999; LESSA, 2005; LESSA \& TOSSO, 2017). Em muitas sociedades, as atividades que envolvem a aquisição de alimentos de origem animal, como caça, proteção de rebanho, açougue e morte, excluem mais ou menos a participação das mulheres (FRANKLIN, 1999). Para pesquisadoras como Adams (2012; 1991) e Lessa (2005), a carne é, ainda hoje, percebida como um atributo essencial na legitimação da masculinidade e uma metáfora da dominação masculina, sendo observado não só no controle da produção, mas também na desigualdade de consumo.

As redes de significado em torno da carne é uma construção que afeta também a forma como olhamos para diferentes animais. De acordo com Joy (2014), estamos inseridos em um sistema de crenças o qual ela denominou de carnismo. Nessa ideologia, existe um acordo tácito que permite que os animais fornecedores de carnes sejam consumidos e tratados de forma distintas daqueles compreendidos como pets, por exemplo. Dessa forma, o que pode ser interpretado como crueldade animal para uns, para outros não. Esse paradoxo da carne, como a autora denomina, é anulado 
pelos “quatro N", ou seja, de que se alimentar de carne é "natural, necessário, normal e bom".

Os animais que fornecem carne, juntamente com outras espécies, estão, portanto, inseridos em redes complexas de relações com os humanos que não só garantem a alimentação destes últimos, como também significam muitas das relações humanas. Em função dessa trajetória conjunta é possível, até mesmo, que nossa história seja narrada pelos animais que colocamos no prato, uma vez que sempre que a história age, ou seja, quando as sociedades humanas assumem outros aspectos, ela afeta a forma como nos relacionamos com os animais e os significados que atribuímos a eles.

Em sociedades de caçadores-coletores e/ou de agricultura doméstica e local as biografias de humanos e animais constantemente se confundem e as relações apresentadas acima são ainda mais estreitas (FRANKLIN, 1999). Contudo, essa trajetória comum que os animais dividem com os humanos que os cercam está ganhando outros contornos e isso está intimamente relacionado com os fatores da modernidade (FRANKLIN, 1999; LEROY \& PRAET, 2017; POLLAN, 2006). Mesmo não existindo um continuum temporal entre uma época em que caçávamos animais, passando por sua domesticação até chegar às formas industriais de produção de carne (LEROY \& PRAET, 2017), esta última assume cada vez mais o modo predominante de obtenção dos produtos cárneos nas sociedades modernas, sobretudo as ocidentais (FRANKLIN, 1999; LEROY \& PRAET, 2017; POLLAN, 2006; STIFTUNG, 2015). Como consequência desse fenômeno, as formas atuais de produção predominante fazem com que humanos e animais fornecedores de carne se tornem quase que estranhos um para o outro e torna duas ações que por muito tempo foram muito próximas em algo totalmente distante: produzir e consumir (FRANKLIN, 1999).

De acordo com o "Atlas da Carne” de 2014 (STIFTUNG, 2015), a produção dos principais animais do regime alimentar humano atual é extremamente concentrada. Os países da região Norte do mundo, por exemplo, estão contando cada vez com menos agricultores. No entanto, isso não significa que a produção está caindo, mas que grandes corporações multinacionais dominam todo o sistema produtivo. As

\footnotetext{
${ }^{2}$ Nice no original em inglês.
} 
consequências disso são enormes, como mostrarei mais adiante, mas de imediato isso significa que os bifes das bandejas de supermercados viajaram muitos quilômetros para chegar até ali. Esse fenômeno que foi iniciado nos Estados Unidos e na Europa a mais de três décadas tem se intensificado em outros países tradicionais de produção de carne, como o Brasil por exemplo.

Essa distância física entre o animal que um dia existiu e a carne da bandeja encontrada no supermercado, muitas vezes, se transforma em uma distância de significado. Este "referente ausente" como denomina Adams (2012) destituí o animal do seu sentido original, transformando-o apenas em pedaços comestíveis. E isso tem um forte impacto não só em suas vidas como animais, mas também como os percebemos dentro desta nova estrutura agroalimentar.

Em sociedades tradicionais os animais domésticos, em geral, tinham sua importância medida muito mais pela sua força de trabalho do que pela sua capacidade de fornecer carne (FRANKLIN, 1999). Durante o século XIX e XX, por outro lado, essa relação se inverte. Enquanto a força de trabalho animal tem sido gradativamente eliminada, a produção e o consumo de carne aumentaram a partir da lógica de controle e exploração industrial (Ibid.).

Como consequência desse sistema de produção de carne a mercadoria se torna mais barata e, portanto, mais acessível (POLLAN, 2006). Mesmo que o seu consumo ainda seja desigual e pedaços distintos ou espécies diferentes ainda sejam marcadores de classe, como é possível observar na última pesquisa de orçamentos familiares realizada no Brasil (IBGE, 2009), ela tem estado cada vez mais presente nos pratos da população mundial. Nos últimos 50 anos praticamente quadruplicou (RITCHIE, 2019). Outro fator que ajuda a explicar esse aumento é a melhoria das condições de vida da população em geral, principalmente relacionada à classe média crescente (STIFTUNG, 2015; RITCHIE, 2019), além da urbanização (LEROY \& PRAET, 2017; STIFTUNG, 2015). Em função disso, a OECD (Organisation for Economic Co-operation and Development) considera o consumo de carne como um indicador de riqueza e desenvolvimento de um país ou região.

No entanto, para que se mantenham essas condições de produção e consumo é necessário que produtores e consumidores tenham que gerir e negociar com os riscos 
que esse sistema industrial gera. De imediato, a produção em larga escala e a consolidação de uma indústria da carne praticamente impede que os pequenos produtores tenham chance de competir com os preços que a as grandes empresas praticam. Adicionalmente, a eficiência produtiva é mantida ainda às custas da saúde dos animais. Para que eles atinjam o ponto de abate o mais rápido possível é necessário que sejam mantidos confinados e as raças e espécies sejam diminuídas a fim de se ter maior controle da produção (STIFTUNG, 2015; POLLAN, 2006). Sendo meras cópias genéticas de si mesmos, esses animais apresentam grandes chances de desenvolver e transmitir doenças. Para controlar esse risco, os produtores aplicam-nos altas doses de antibióticos. A principal consequência disso, infelizmente, não é a erradicação das doenças, mas a possibilidade de desenvolvimento de superbactérias, um risco que tanto humanos quanto animais estão sujeitos (FRANKLIN, 1999; POLLAN, 2006; STIFTUNG, 2015).

Além disso, são associados à produção de proteína animal consequências negativas ao meia ambiente como a diminuição de ecossistemas e florestas. Outros problemas ambientais decorrentes da produção de carne, para citar alguns, são a diminuição da biodiversidade em função do desmatamento e da falta de variabilidade genética dos animais fornecedores de carne; morte da biodiversidade aquática e infertilidade do solo em função da alta concentração de nitrato decorrente do esterco excessivo que se espalham facilmente quando atingem os lençóis freáticos; o uso desmedido de fertilizantes em capins e na produção de grãos que são usados na alimentação dos animais; além da quantidade excessiva de água consumida durante todo o processo produtivo (DUARTE, 2008; POLLAN, 2006; STIFTUNG, 2015). Nesse sentido, o preço baixo das asinhas de frango ou do bife da bandejinha de supermercado é mantido às custas da pobreza, da saúde dos animais e do meio-ambiente.

As consequências da produção industrial de carne estão intimamente relacionadas às tendências da modernidade apontadas por Beck (2011). A lógica de produção de riquezas foi substituída pela da produção de riscos que, diferente da primeira, não é limitado geograficamente. Eles ultrapassam as fronteiras nacionais e "faz surgir ameaças globais supranacionais e independente de classe" (BECK, 2011, p. 16 grifo do autor). Como parte desse processo, o conhecimento especializado e as 
instituições produtoras de conhecimento perdem a confiabilidade, especialmente porque elas são vistas como inadequadas e incapazes de gerenciar os riscos que a modernidade cria (BECK, 2011; GIDDENS, 2002). O resultado disso é que o gerenciamento dos riscos se torna uma responsabilidade individual. Na sociedade moderna e individualizada, os "especialistas acabam descarregando suas contradições e controvérsias sobre o indivíduo e confiam-lhe, no mais com a melhor das intenções, a tarefa de avaliar tudo isso criticamente com bases nas próprias ideias" (BECK, 2011, p. 201). Dessa forma, a decisão de colocar aquela bandeja de carne dentro do carrinho de supermercado implica em aceitar os riscos que ela pode ter para a nossa saúde ou cooptar com as consequências sociais, econômicas e ambientais que ela gera. Uma decisão individual acaba levando a culpa por toda uma lógica produtiva. O indivíduo, nesse caso, "é elevado a um trono fictício de reformador do mundo" (BECK, 2011, p. 202). Nesse sentido, muitas das formas de cidadania praticadas pelos indivíduos acabam passando pelas decisões de compras (JOHNSTON \& SZABO, 2010). Embora muitos consumidores que conhecem os impactos da produção de carne na modernidade decidem ignorá-los em favor do seu prazer pessoal (OLESCHUCK et al, 2019), o crescente número de vegetarianos assumem uma posição crítica em relação à eles assumindo uma identidade que, de acordo com Giddens (2002), pode ser compreendida como uma política-vida. É sobre isso que será discutido na próxima sessão.

\section{A construção da identidade vegetariana: interações com uma política-vida?}

Desde a ascensão da modernidade, a estrutura social tem se definido a partir de sua característica dinâmica e globalizada, alterando significativamente os hábitos e costumes tradicionais e, consequentemente, a percepção individual de estar no mundo. Pelas lentes de Giddens (2002) e Beck (2011), a modernidade se caracteriza como uma sociedade pós-tradicional em que a identidade não é mais limitada pelos princípios da tradição, do parentesco e da localidade, mas pelo cultivo das potencialidades individuais. Ao ser definida como pós-tradicional, as instituições modernas constroem novos mecanismos de autoidentificação que também são 
construídos por elas e, portanto, são sempre móveis e mutáveis. É, dessa forma, que na modernidade o "eu" se configura como um projeto reflexivo, uma vez que sem o referencial da tradição, são oferecidos um universo diverso de possibilidade e escolhas construídos pelos sistemas abstratos de conhecimento. A identidade e o planejamento estratégico da vida assumem uma responsabilidade individual, embora suas consequências possam ser globais. (BECK, 2010; GIDDENS, 2002).

A partir dessa prerrogativa, os hábitos alimentares também podem assumir características reflexivas em que não mais a tradição, mas os sistemas abstratos de conhecimento passam a nortear as escolhas do que comer. Estes, ao construírem saberes sobre os aspectos que envolvem o ato de se alimentar, práticas e costumes são permanentemente revistos e alterados, produzindo um novo modo de organizar a alimentação, bem como a forma que os sujeitos se identificam com ela (KUWAE et al, 2016).

Um estudo comparativo entre várias países denominado OCHA3 (FISCHLER \& MASSON, 2010) é um indicativo dessa tendência. Os resultados demonstraram uma concepção mais individualizada da alimentação, sobretudo em países cuja culinária não tem um forte apelo tradicional e reconhecimento internacional. Os americanos, por exemplo, tendem a orientar suas práticas a partir de escolhas individuais vinculadas ao exame de informações divulgadas sobre a alimentação. A produção e disponibilidade dos saberes médico-científicos capacitam e informam os indivíduos, que passam a orientar suas práticas por esse conhecimento (Ibid.). A diversidade de informações produzidas em torno da alimentação sob a forma de saberes científicos ou pela divulgação midiática, bem como a maior oportunidade de acesso a produtos alimentares distintos em função, sobretudo, da industrialização e da globalização, resultam na produção de um novo léxico alimentar. Palavras como diet, veg, gourmet, saudável, orgânico entre outras passam a fazer parte do vocabulário que norteiam a comida alargando os critérios da organização alimentar (LIRA, 2013).

Essa "cacofonia alimentar" é apontada por Fischler (1995) como resultado de uma multiplicação de agentes e discursos em torno da alimentação acarretando, com isso, em práticas desorganizadas e contraditórias que, muitas vezes, confundem os

3 Observatório Cniel de Hábitos Alimentares 
indivíduos. Essa percepção do autor lança luz ao fato de que ao desnaturalizar a alimentação e trazer para o indivíduo a responsabilidade da escolha dos alimentos, alimentar-se passa a ser um exercício reflexivo cotidiano que, por não ser ancorado em nenhuma certeza tradicional, alimenta incertezas e sentimentos de ansiedade. As palavras de Lira (2013), traduzem de forma satisfatória essa situação:

O fenômeno denominado por Fischler, em 1979, de gastro-anomia define o modo como lidamos com a comida contemporaneamente nas sociedades ocidentais modernas, incluindo uma preocupação constante com os componentes alimentares, tendo em vista o poder de transferência desses alimentos para o corpo e as consequências de sua ingestão para saúde, imagem e/ou performance física. As regras alimentares que têm como base o potencial nutritivo dos alimentos e sua capacidade de converter-se em substâncias e volumes corporais, como gordura, músculos, enzimas, proteínas, calorias, etc., passaram a ocupar o lugar de importância concedida a critérios mais automatizados pela tradição e cultura, como os referentes à comensalidade e a busca pelo prazer, tanto da partilha e do ritual quanto da experiência sensorial dos sabores e gostos familiares e inusitados. A individualização do ato de comer, que constitui esse processo, torna difícil a escolha diante da quantidade e diversidade de informações, muitas vezes, conflitantes, sobre as propriedades de cada alimento e dieta a ser seguida. $\mathrm{O}$ comedor moderno, de acordo com essa ideia, passa a experimentar uma insegurança e desconfiança constante ao se deparar com o cardápio (LIRA, 2013, p. 73 grifo da autora).

Essa ansiedade experienciada pelos indivíduos é, segundo Giddens (2002), a consequência de um mundo em que a consciência do risco está sempre presente. Tais ansiedades não são geradas por algum risco iminente ou real na vida diária, mas sim pela própria necessidade de calcular os riscos, que muitas vezes estão tanto geograficamente quanto temporalmente distantes, mas, como dito anteriormente, o seu gerenciamento se torna uma responsabilidade individual. Apesar dos sistemas abstratos fornecerem uma pequena confiança em relação às decisões a serem tomadas, eles também contribuem na alimentação da insegurança cotidiana. Em tempos de cultura da informação e multimídia, os saberes produzidos, sejam técnico-científico ou leigos, circulam de forma rápida e percorrem longas distâncias alterando radicalmente a experiência de estar no mundo (LIRA, 2013). Os processos transformadores da modernidade não podem ser separados das influências globalizantes, dessa forma, por mais que estejamos limitados a um tempo e em espaço, nossas experiências são atravessadas por influências que estão distantes de nós. 
Diante dessa incerteza institucionalizada há uma diversificação das formas que os indivíduos se orientam a fim de constituir seu estilo de vida. Em momentos decisivos, afirma Giddens (2002), as pessoas podem tanto escolher se refugiar em modelos tradicionais de autoridades, como crenças religiosas e crenças familiares, ou, por outro lado, se reapropriar dos saberes por meio da qualificação e do empoderamento.

Momentos decisivos são o ponto de transição que tem implicações não só para a conduta futura, mas para a auto-identidade. Pois a decisões de consequência, uma vez tomadas, refazem o projeto reflexivo da identidade pelas consequências que ocasionam para o estilo de vida" (GIDDENS, 2002, p. 134).

A identidade alimentar na modernidade tardia pode ser entendida sob os mesmos parâmetros. Alimentar-se faz parte de um projeto reflexivo cujas escolhas contribuem para e elaboração de um estilo de vida. Dentro desse processo de escolhas, os indivíduos podem seguir uma dieta baseada em preceitos religiosos, em tradições familiares, pela culinária regional, pelos ditames dos saberes abstratos ou a partir de suas próprias capacitações. No entanto, todas derivam de uma resposta ao modo moderno de produzir e significar os alimentos.

Essas escolhas que, aparentemente, dizem respeito a apenas um nível privado e localizado da vida podem, ainda, serem tangenciadas por critérios que convencionalmente dizem respeito à esfera pública. Em outras palavras, a adoção de uma dieta específica pode não ser resultado exclusivamente de preocupações egoístas. Muitas pessoas acabam restringindo suas escolhas alimentares em função de questões morais ou éticas se engajando no que Giddens (2002) denominou de política-vida. A política de vida, conforme Giddens (2002), diz respeito a uma atuação política atrelada ao processo de subjetivação e de construção da autoidentidade que se distingue dos modos tradicionais de luta política emancipatória, caracteristicamente atrelados às identidades coletivas, como partidos, classes ou sindicatos, por exemplo.

A política-vida refere-se a questões políticas que fluem a partir de processos de auto-realização em contextos pós-tradicionais, onde influências globalizantes penetram profundamente no projeto reflexivo do eu e, 
inversamente, onde os processos de auto-realização influenciam as estratégias globais (GIDDENS, 2002, p. 196).

Em um sentido amplo, trata-se de uma forma de agir e estar no mundo que amplia os propósitos a respeito das questões morais, estéticas ou filosóficas, se configurando como um tipo de política que diz respeito à vida cotidiana, da intimidade. Nesse sentido, é uma política do estilo de vida em que a esfera pessoal passa a ser significada como política. "É uma política de autorrealização num ambiente reflexivamente organizado, onde a reflexividade liga o eu e o corpo a sistemas de alcance global" (Ibid.). Com base nisso, é possível afirmar que o estilo de vida vegetariano pode ser compreendido com uma política-vida?

As dietas restritivas sempre fizeram parte da matriz cultural de diversos grupos (ABONIZIO, 2016). No entanto, seu significado, na maior parte das vezes, esteve atrelado a questões religiosas, culturais ou morais de tais grupos. Na modernidade tardia elas foram ressignificadas, onde a moralidade, a saúde ou a cultura são expressas no nível individual. Ser vegetariano nas sociedades modernas é, nesse sentido, um reflexo que diz respeito sobretudo às experiências reflexivas em um mundo globalizado e menos uma conduta baseada em uma tradição (ibid.). A sedimentação das experiências atreladas ao conjunto de informações obtida, bem como a interpretação individual desses dois elementos, orienta a ação e o projeto de vida de cada sujeito, fazendo com que, muitas vezes, a ordem social e cultural seja contestada (LIRA, 2013). De fato, na maior parte dos contextos, a adoção de uma dieta baseada em plantas se configura como uma posição crítica da cultura alimentar partilhada e dos modos de produção dos alimentos vigentes. Dessa forma, essas pessoas estariam envoltas em produções de novos estilos de vidas e práticas de consumo que se adequam a uma nova moralidade (TRIGUEIRO, 2013) em relação aos animais, à relação com a natureza e a cultura, bem como com o sistema agroalimentar e, portanto, elas se adequam ao que Giddens (2002) denomina de um estilo de vida político.

No entanto, de acordo com Micheletti \& Stolle (2010), para responder a essa pergunta é necessário compreender o motivo que levou o indivíduo a adotar essa dieta. O vegetarianismo não é uma categoria fechada. Há tantas formas de exercer a identidade vegetariana quanto os motivos que levam alguém a exercer esse modo de 
vida. As razões frequentes em geral, se enquadram entre evitar o abate e a preocupação com a própria saúde (ABONIZIO, 2016). Internos a essas categorias generalizantes, são apontadas como razão do vegetarianismo preocupações com o tratamento dos animais nas fazendas, o impacto da criação de animais nas mudanças climáticas globais, o consumo de carne como atributo de intensificação da pobreza, a visão ética de que os animais têm direito à própria vida, além de questões religiosas e o bem estar humano decorrente da abolição da proteína animal da dieta (MICHELETTI \& STOLLE, 2010; FERRIGNO, 2012). Essas diferentes motivações são resultado das distintas experiências que os comensais vegetarianos tiveram diante do que se comia, bem como das informações que tiveram acesso a respeito do que se alimentar, levando, com isso, a atribuições e sentidos distintos em relação à carne (ABONIZIO, 2016).

Para Micheletti e Stolle (2010) a adoção de uma dieta baseada em plantas só pode ser compreendida como um estilo de vida político quando a razão para a adotar não resida em questões pessoais, como a melhora da saúde, por exemplo. Para os autores, somente quando a adoção da dieta for motivada por questões políticas, éticas e morais que ela pode ser considerada como constituinte de um estilo de vida político. Com base nisso, a prática vegana seria a forma que melhor representa a adoção de uma política-vida entre os vegetarianos por desenvolver uma consciência que atrela o consumo à valores e atitudes políticos, sociais e ambientais.

A separação entre os vegetarianos-saúde (health vegetarian) e vegetarianoséticos (ethical vegetarian) (FESSLER et al, 2003; ABONIZIO, 2016) são categorias analíticas muito difundidas entre os estudiosos desse movimento, contudo, tendo a considerar que tanto um quanto o outro poderiam se encaixar em um estilo de vida política. Revisando o conceito de política-vida de Giddens (2002) o autor tenta deixar claro que ele diz respeito a uma política de decisões da vida que derivam do projeto reflexivo do eu. Portanto, a política-vida é uma consequência da construção da autoidentidade, deixando menos claras as barreiras que separam o que é político e o que é pessoal. Como Lira definiu, ser vegetariano é uma experiência encarnada no mundo da vida, cujas sensações físicas, emocionais e corporais interagem diretamente com a cultura e, eu adicionaria, as estruturas sociais. 
Ao limitar os vegetarianos-saúde a uma esfera pessoal e privada, Micheletti \& Stolle (2010) negam o fato de que o corpo e a forma de o cuidar é interseccionado pela esfera pública. O corpo é um constituinte da autoidentidade e, portanto, está inserido na reflexividade da modernidade. Como Giddens (2002) destaca, na modernidade o corpo era tomado como um dado, um elemento natural que deveria ser governado. Contudo, ao ser invadido pelos sistemas abstratos, ele se torna "o lugar da interação, apropriação e reapropriação, ligando processos reflexivamente organizados ao conhecimento especializado sistematicamente ordenado” (GIDDENS, 2002, p. 200). Uma vez que o corpo passa a interagir com as influências globalizantes da modernidade tardia, ele se configura como um elemento da política-vida.

Ser vegetariano com a justificativa de melhorar a saúde, portanto, pode sim ser considerado uma forma de política-vida, pois, assim como o vegetarianismo-ético, é resultado de uma relação reflexiva com as crenças vigentes e os conceitos norteadores da prática alimentar. Mesmo que a razão para adoção dessa dieta não resida no bem estar animal, nas preocupações ambientais ou na desigualdade planetária, a prática é orientada por uma ação reflexiva em relação ao próprio corpo e aos sistemas abstratos que tentam apropriá-lo. Afirmar que uma dieta baseada em plantas é mais saudável, é negar toda uma cultura médica que dá protagonismo à proteína animal como recurso crucial para manter a boa saúde. É, ainda, uma forma de se reapropriar do próprio corpo e agir reflexivamente sobre ele, orientando as ações com base nessa decisão. Além disso, como procurei mostrar na seção anterior, os riscos provenientes de um sistema industrial de produção de carne dizem respeito também sobre a saúde humana. Desse ponto de vista, a escolha de abdicar do consumo de proteína animal em função da saúde é propor uma percepção distinta em torno dela e do sistema produtivo que a envolve.

\section{Considerações finais}

Alimentar-se na modernidade tardia pode ser compreendida como uma prática reflexiva que se enquadra no processo de construção de uma autoidentidade dos sujeitos modernos. Diferentemente das sociedades tradicionais, decidir o que 
comer no jantar pode se configurar como uma ação que reflete posicionamentos políticos, preocupações com a saúde ou com questões ambientais, por exemplo. A produção industrial de carne, por exemplo, apesar de proporcionar uma maior democratização do consumo de proteína animal, produz uma quantidade infinita de riscos para os humanos, os animais e o meio ambiente. Contudo, em sociedades individualizadas recai sobre os indivíduos de gerenciar e se posicionar em relação a esses riscos que a modernidade tardia cria.

Em meio a isso, o meu objetivo foi propor abordar a adoção da identidade alimentar vegetariana a partir do conceito de política-vida de Giddens (2002). Essa análise procurou alargar o entendimento sociológico da adoção de uma dieta em plantas como um fenômeno que traduz a natureza específica da ação nas sociedades contemporâneas, sobretudo as ocidentais. Essa forma de fazer política centrada no indivíduo se configura a partir da produção de novas biografias e de novos engajamentos intersubjetivos, acarretando identidades culturais fluidas e abertas. Nesse contexto, questões referentes ao corpo e ao estilo de vida ganham importância por refletirem posições reflexivas a respeito das informações e das influências globalizantes.

É em função disso que considerei que as duas grandes categorias que segregam os vegetarianos, a saber o vegetarianismo-ético e o vegetarianos-saúde, podem ser compreendidas como uma manifestação da política-vida na modernidade tardia. Isso porque, ambos constroem sua identidade a partir de uma apropriação reflexiva dos saberes e das influências que norteiam as práticas alimentares que, apesar de localizada, são globais em suas consequências. A escolha por abolir a carne animal do montante dos alimentos possíveis destinados à alimentação é perpassado por questões que vão desde os interesses mais particulares até os mais públicos. No entanto, todos são baseados em escolhas que, de alguma forma, representa uma forma reflexiva de estar no mundo, exigindo que suas identidades tenham representatividade e sejam respeitadas tanto no espaço privado, como no público. Isso demonstra que, na modernidade tardia, o pessoal é sim político e vice e versa. Essas barreiras compreendidas anteriormente como essencialmente separadas estão cada vez mais difusas. O estudo do comportamento alimentar na contemporaneidade pode, a meu 
ver, contribuir para o entendimento de como elas se auto influenciam e operam, além de alargar o entendimento de como os indivíduos significam aquilo que colocam no prato, como os animais, por exemplo.

\section{Referências}

ABIEC, Associação Brasileira das Indústrias Exportadoras de Carne. Perfil da Pecuária no Brasil - Relatório Anual. Edição on-line, 2018. Disponível em: http://www.abiec.com.br/Sumario.aspx. Acesso em 11 nov. 2018.

ABONIZIO, Juliana. Conflitos à mesa: vegetarianos, consumo e identidade. Rev. bras. Ci. Soc., São Paulo, vol 31, n. 90, p. 115-136, Feb. 2016.

ADAMS, Carol J. A política sexual da carne: A relação entre o carnivorismo e a dominância masculina. São Paulo: Alaúde Editorial, 2012.

ADANS, Carol J. Ecofeminism and the Eating of Animals. Hypatia, vol 6, n. 1, p. 125145, Mar - Jun. 1991.

BEARDSWORTH, A; KEIL, T. Sociology on the Menu: An Invitation to the Study of Food and Society. Londres: Routledge, 1997.

BECK, Ulrich. Sociedade de risco: rumo a uma outra modernidade. São Paulo: Editora 34, 2011.

BLADES, Mabel. Factors Affecting What We Eat. Nutrition \& Food Science, vol 31, n. 2, p. 71-74. 2001.

BOURDIEU, Pierre. A distinção: crítica social do julgamento. São Paulo: EDUSP, 2007.

CAMPHORA, Ana Lucia. Animais e Sociedade: no Brasil dos séculos XVI ao XIX. Rio de Janeiro, 2017.

CÂNDIDO, Antônio. Os parceiros do Rio Bonito. São Paulo: Duas Cidades, 2001.

DUARTE, Ilka de Sousa. Impactos ambientais da produção de carne para consumo humano: a indústria da carne na contramão da tutela constitucional do meio ambiente. 2008. 117 p. Monografia (Graduação em Direito)-Faculdade de Direito do Recife, Universidade Federal de Pernambuco, Recife, 2008.

FERRIGNO, Mayra Vergotti. Veganismo e libertação animal: um estudo etnográfico. 2012. 28o p. Dissertação (mestrado) - Universidade Estadual de Campinas, Instituto de Filosofia e Ciências Humanas, Campinas, SP. Disponível em: 
<http://www.repositorio.unicamp.br/handle/REPOSIP/279340>. Acesso em: 20 ago. 2018.

FESSLER, D. et al. Disgust sensitivity and meat consumption: a test of an emotivist account of moral vegetarianism. Appetite. Los Angeles, vol 41, n. 1, p. 31-41. 2013.

FIDDES, Nick. MEAT: A Natural Symbol. New York: Taylor \&amp; Francis e-Library, 2004 .

FISCHLER, C, El (h)omnívoro. Barcelona: Editorial Anagrama, 1995.

FISCHLER, C.; MASSON, E. Comer: a alimentação entre os franceses, outros europeus e americanos. São Paulo: Senac, 2010.

FRANKLIN, Adrian. Animal and modern cultures: a sociology of human-animal relations in modernity. Londres: SAGE Publications, 1999. (ebook).

GAARD, Greta. Vegetarian Ecofeminism: A Review Essay. Frontiers: A Journal of Women Studies, vol 23, n. 3, p. 117-146, 2002.

GIDDENS, Anthony. Modernidade \& Identidade. Rio de Janeiro: Jorge Zahar, 2003.

GUTHMAN, Julie. Commentary on teaching food: Why I am fed up with Michael Pollan et al. Agriculture and human values, v. 24, n. 2, p. 261-264, 2007.

IBGE, Instituto Brasileiro de Geografia e Estatística. Pesquisa de Orçamentos Familiares (POF), 2009

IBOPE. Dia Mundial do Vegetarianismo: 8\% da população brasileira afirma ser adepta do estilo. Ibope, São Paulo, 1 out. 2012. Disponível em:https://www.ibope.com.br/pt-br/noticias/Paginas/Dia-Mundial-do-

Vegetarianismo-8-da-populacao-brasileira-afirma-ser-adepta-ao-estilo.aspx Acesso em: o2 dez. 2018.

IBOPE. 14\% da população se declara vegetariana. Ibope, São Paulo, 21 mai. 2018. Disponível

em:

http://www.svb.org.br/images/Documentos/JOB_o416_VEGETARIANISMO.pdf.

Acesso em: 20 jan. 2019.

JOHNSTON, J.; SZABO. M. Reflexivity and the Whole Foods Market consumer: the lived experience of shopping for change. Agriculture and Human Values, v. 28, n. 3, p. 303-319, 2011. Disponível em: https://joseejohnston.files.wordpress.com/2014/10/johnston-szabo-ag-humanvalues.pdf. Acessado em: 2 set, 2019. 
JOY, Melanie. Por que amamos cachorros, comemos porcos e vestimos vacas. São Paulo: Cultrix, 2014;

KUWAE, CA., et al. A reflexividade no saber leigo sobre as práticas alimentares. In: PRADO, SD., et al. orgs. Estudos socioculturais em alimentação e saúde: saberes em rede. [online]. Rio de Janeiro: EDUERJ, 2016. Sabor metrópole series, vol. 5, pp. 3357 .

LEROY, Frédéric; PRAET, Istvan. Animal killing and postdomestic meat production. Journal of Agricultural and Environmental Ethics, v. 30, n. 1, p. 67-86, 2017. Disponível em: https://link.springer.com/article/10.1007/s108o6-017-9654-y. Acessado em: 5 set, 2019 .

LIMA. Claudia. Tachos e Panelas: historiografia da alimentação brasileira. $2^{\underline{a}}$ ed. Recife: Ed. da Aurora, 1999.

LIRA, Luciana Campelo de. Limites e paradoxos da moralidade vegan: um estudo sobre as bases simbólicas e morais do vegetarianismo. 2013. Tese (doutorado) Universidade Federal de Pernambuco, Centro de Filosofia e Ciências Humanas, Recife, PE. Disponível em: https://repositorio.ufpe.br/handle/123456789/27495. Acesso em: 02 mar. 2019

Mercado vegano cresce $40 \%$ ao ano, saiba como investir, MarkEsalk. Disponível em: https://markesalq.com.br/2018/o4/o6/mercado-vegano/. Acesso em: 11 mar. 2019.

MICHELETTI, M; STOLLE, D. Vegetarianism-A Lifestyle Politics? In: MICHELETTI, M; MCFARLAND, A. Creative Participation: Responsibility-Taking in the Political World. Colorado: Paradigm Publishers, 2010.

MONTANARI, Massimo. Comida como Cultura. São Paulo: Editora Senac, 2008.

MONTEIRO; Lorena L. C.; GARCIA, Loreley G. Veganismo, feminismo e movimentos sociais no Brasil. In: Seminário Internacional Fazendo Gênero 10 (Anais Eletrônicos), Florianópolis, 2013. Disponível em: http://www.fg2013.wwc2017.eventos.dype.com.br/resources/anais/20/1373336039_ARQ UIVO_MONTEIRO,LorenaL.C.VEGANISMO,FEMINISMOEMOVIMENTOSSOCIAISN OBRASIL.pdf. Acesso em: o1 nov. 2018.

OCDE, Organização para Cooperação e Desenvolvimento Econômico. Meat Consumption. OCDE Data, 2017. Disponível em: https://data.oecd.org/agroutput/meat-consumption.htm. Acessado em: 16/11/2018.

OLESCHUK, Merin; JOHNSTON, Josée; BAUMANN, Shyon. Maintaining Meat: Cultural Repertoires and the Meat Paradox in a Diverse Sociocultural Context. In: 
Sociological Forum. 2019. Disponível em: https://onlinelibrary.wiley.com/doi/abs/10.1111/socf.1250o. Acessado em: 03 set. 2019.

POLLAN, Michael. O dilema do onívoro. Editora Intrínseca, 2007.

POULAIN, Jean-Pierre. O espaço social alimentar: um instrumento para o estudo dos modelos alimentares. Revista de Nutrição, Campinas, v. 16, no 3, p. 245-256 jul./set., 2003.

SOLER, Rodrigo Diaz de Vivar. Fetichismos da carne: consumismo midiático no capitalismo contemporâneo.Estação Científica (UNIFAP), v. 6, n. 2, p. 53-65, 2016. Disponível em: https://periodicos.unifap.br/index.php/estacao/article/view/1855. Acessado em: 19 set. 2019 .

STIFTUNG, Heinrich Böll. Atlas da carne: fatos e números sobre os animais que comemos. Rio de Janeiro: Heinrich Böll Foundation, 2015.

TRIGUEIRO, Aline. Consumo, ética e natureza: o veganismo e as interfaces de uma política de vida. Revista Internacional Interdisciplinar INTERthesis, v. 10, n. 1, p. 237-260, 2013. Disponível em: https://periodicos.ufsc.br/index.php/interthesis/article/view/25643. Acessado em: 13 dez 2018.

USDA, United States Department of Agriculture Economic Research Service. Agricultural Baseline Projections. Edição on-line, 2018. Disponível em: http://www.ers.usda.gov/topics/farmeconomy/agriculturalbaselineprojections.aspx.

Acesso em: 11 out. 2018.

Vegetarianism in America, Vegetarian Times. 2017. Disponível em: https://www.vegetariantimes.com/uncategorized/vegetarianism-in-america. Acesso em: 15 abr. 2019.

Vegetarianismo, Sociedade Vegetariana Brasileira. Disponível em: https://www.svb.org.br/vegetarianismol/o-que-e. Acesso em: 23 mar. 2019.

WESP-GUTERRES, Caroline; TEIXEIRA, José Domingos Lemos; ARALDI, Daniele. F. Produção de Carne Bovina e Consumo Interno Brasileiro. XVIII Seminário Interinstitucional de Ensino, Pesquisa e Extensão, XVI Mostra de Iniciação Científica e XI Mostra de Extensão, 2013. Disponível em: https://home.unicruz.edu.br/seminario/anais/anais2013/XVIII\%20SEMIN\%C3\%81RIO\%20INTERINSTITUCIONAL\%202013\%20\%20ANAIS/CCAET/AGRONOMIA/C.\%20Oral/PRODU\%C3\%87\%C $3 \% 83 \mathrm{O} \% 20$ DE\%20 CARNE\%2oBOVINA\%2oE\%2oCONSUMO\%2oINTERNO\%2oBRASILEIRO.pdf. Acessado em: 05 mai. 2019. 